\title{
It Takes a Village: Empowering Chinese Immigrant Families of Children with Disabilities
}

\author{
Dr. Lusa Lo \\ University of Massachusetts Boston, United States
}

\begin{abstract}
Policy makers, researchers, and practitioners unanimously agree about the positive impact of parent involvement on students. When parents are actively engaged in their children's academic career, their children are more likely to perform well in school academically, socially, and behaviorally. Parent engagement is especially important in special education. Due to their understanding of their child's needs, strengths, and weaknesses, parents of children with disabilities are expected to not only serve as their children's caretakers but

also as their advocates. Due to budget constraints, many school districts struggle to effectively engage and support their families of children with disabilities. Support from

the community is needed, especially for one from diverse background. The purpose of this mixed-method study is to share the impact of a community parent support group on the knowledge and skills of 58 Chinese immigrant families about navigating the special education process and advocating for appropriate services and placement for their children with disabilities. Both survey and interview were used. Results of the study indicated that the parent participants not only gained knowledge and skills that equip them to be their children's advocates but were also empowered to take parent leadership roles in the community. Parents are important members in their child's special education program development team. Their involvement and participation in the team helps schools ensure that the services and supports they provide

to the students are appropriate. The ones who benefit are the children with disabilities.
\end{abstract}

Keywords: community; diversity; empowerment; parent engagement; special education 